\title{
Guías de campo y registro etnográfico. Una re- visión del abordaje de los niños y niñas desde la Guía para la clasificación de los datos culturales
}

\author{
NoElia ENRIZ
}

\begin{abstract}
resumen Los estudios que tuvieron como epicentro la comparación de grupos poblacionales han formado parte del esquema vertebral de la antropología como disciplina. En el marco de los estudios interesados por la comparación, el uso de guías de campo en los estudios etnográficos locales ha sido regular a mediados del siglo XX. En este trabajo nos proponemos abordar el contexto y el modo de producción de las mismas, tomando como eje de análisis la guía de George Murdock, por haber sido herramienta en la formación local de antropólogos, en los inicios de la antropología como carrera de estudios sistematizada. El abordaje tendrá como eje central considerar particularmente el lugar otorgado a los niños y nińas en la guía de Murdock. Consideraremos el contraste entre dicho abordaje y las actuales perspectivas de estudio de estos grupos poblacionales.
\end{abstract}

palabras-clave Etnografía. Historia de la teoría. Guías de campo. Antropología local. Antropología de la Infancia.

\section{Introducción}

El interés de la antropología por pensar la alteridad ha sido una marca disciplinar desde los comienzos de la consolidación de la antropología a finales del s. XIX. Claro está que ese interés no se expresó del mismo modo a lo largo del tiempo, dado que la conceptualización sobre los sujetos ha variado a lo largo del desarrollo de las distintas corrientes y escuelas que agruparon la producción de contenidos específicos del área.

Pero, va de suyo que el interés por pensar otros, dio lugar a una amplia variedad de abordajes, desarrollos teóricos y metodologías. Un aspecto que se sostuvo a lo largo del tiempo ha sido el interés por pensar relaciones de esos otros entre sí o bien con un nosotros, ya sea que fueran pensadas de modo explícitamente comparativo o no.

$\mathrm{Si}$ bien las investigaciones enmarcadas en el evolucionismo y difusionismo han dado un lugar central a la comparación, esto ha sido en términos bis a bis. En cambio, el abordaje de la escuela de cultura y personalidad ha contemplado los contrastes con el objetivo de dar lugar a una reflexión que permitiera a la sociedad norteamericana de la época reconocer otros modos posibles de experimentar la vida. Un aspecto sobre el que esta corriente tuvo gran énfasis, es el estudio dedicado a los niños y niñas, dónde su diálogo con la psicología perseguía el objetivo de sacar de escena el modelo homogéneo de niño.

Los abordajes de la escuela de cultura y personalidad lograron superar dos fuertes tensiones, criticadas en las teorías clásicas de la comparación. Por un lado, superaron la perspectiva centrada en el modelo europeo occidental de 
fines del siglo XIX. Es decir, trascendieron el modelo etnocéntrico y dieron lugar a una lectura mucho más compleja de la sociedad. A su vez, por las transformaciones que la propia disciplina supuso, el aporte que éstas hicieron a la conceptualización de diversos modos de vida significó una importante contribución a los estudios de género, en auge en la época (Moore, 1999; Lamas, 1986). Del mismo modo, contribuyeron a los estudios dedicados a lo político (Gledhill, 2000; Balandier, 2004).

Son especialmente interesante los abordajes de la cuestión de género en las teorizaciones de Margaret Mead (ver especialmente 1985) que permiten conceptualizar las diversas formas en que se construyen las nociones de género en sociedades particulares. En esta misma línea es importante considerar los estudios relativos a la niñez (Whiting \& Whiting, 1975), una obra dedicada a considerar las implicancias de diferentes ambientes de aprendizaje en el comportamiento social de niños.

Quizá el conflicto teórico de mayor relevancia realizado a los estudios mencionados ha sido aquel que cuestionara el modelo relativista, resultante de estos abordajes comparativos. El cuestionamiento mas agudo al respecto sostiene que la reflexión relativista podría dar lugar a contemplar como culturalmente admitido cualquier tipo de vejámenes que una sociedad practicara a lo largo del tiempo (Frow, 1992; Alvargonzález, 1999). Es que la discusión entre universalismos y particularismos no parece nunca zanjada en nuestra disciplina, ya que siguiendo a DaMatta todos los investigadores pasamos por un momento "cuando nuestra preocupación pasa de las teorías más universales a los problemas más banalmente concretos" (DaMatta, 2004, p. 168).

Este trabajo abordará la tensión entre lo universal y lo particular en un caso concreto de propuesta metodológica, las guías de campo. Tan utilizadas en nuestro continente a mediados del 1900, tan relevantes para la formación de nuestros profesores y tan invisibles en la actualidad. Pondremos nuestra atención en la guía Murdock, su desarrollo, historia y alcances como material de investigación.

\section{Historia de las guías y manuales de antropología}

Como parte de los intereses de la antropología como disciplina en el contexto de desarrollo de las escuelas nacionales, en el período de entreguerras, surgen los soportes metodológicos que nos proponemos indagar en este trabajo, las guías de campo. El caso concreto que será de nuestro análisis, nos permitirá comprender en qué medida estos soportes de investigación subsidiaron los avances bélicos del segundo período de guerras mundiales.

Las guías de campo han sido manuales de trabajo en campo para antropólogos, cuyo objetivo central ha sido pautar los elementos que es necesario relevar a la hora de realizar trabajo de campo. En tal sentido, las guías han sido un modelo de clasificación, es decir un esquema que eventualmente permitiría acceder a características generales necesarias para conocer cualquier población y que a la vez permitirían cotejar los mismos elementos en distintas sociedades. Claro que esta posibilidad de constituir un esquema que viabilice la comparación es, si no falsa, en cierta medida ilusoria o al menos muy difícil de llevar a cabo. La mayor complejidad de la pretensión de comparación reside justamente en el dilema que implica traspasar ciertos datos de las poblaciones a dicho esquema, ya que eso implica una traducción de sentidos solo asegurad"a por el punto de vista del investigador (Geertz, 2001). 
Y es la percepción individual la que dista de habilitar taxonomías rígidas o bien categorías cerradas. Muy por el contrario puede convertirse en un esquema infinito de abordaje de una población ya que, la cantidad y densidad de la información requerida puede suponer una enorme exhaustividad en la tarea. Implicando no solo recuperar la información necesaria, sino comprender los sentidos sociales otorgados a dichos términos para luego catalogarlos. Esta tarea, además de sus dimensiones, presenta otras dos dificultades. La primera, es que si se consideran las perspectivas nativas, se deja de lado el esquema de organización per se de la propia guía. Puede derivarse de esta misma la imposibilidad del cotejo con otros pueblos indagados del mismo modo.

Pero por otro lado, deja poco margen para dar cuenta de las transformaciones culturales, ya que invita sugestivamente a describir de forma cerrada la cultura de un grupo. Volveremos sobre este tema, cuando abordemos el caso concreto de análisis.

Para que la guía funcione como tal, es decir como esquema, debe ser interpretada desde perspectivas comunes, muy posiblemente la de los investigadores que emprenden la tarea etnográfica. Esta forma de abordaje, dejaría nuevamente a los investigadores a un paso de las críticas al modelo evolucionista, en tanto la posibilidad de caer en etnocentrismos parece casi insalvable. Por tanto la guía pendula entre las posibilidades que ofrece, su eficacia y las flexibilidades, utilidades y demandas concretas que exige necesariamente su ejercicio cotidiano, en el contexto de la antropología de postguerra.

La posibilidad de registrar estos elementos en el estricto seguimiento de los elementos propuestos podría dar lugar a una enorme fragmentación de la información. Si bien el ejercicio científico de recopilación puede suponer la escisión de elementos de análisis, la dispersión de la información producida a través de esta técnica puede atentar incluso contra su potencial.
Como dijimos anteriormente, en este trabajo nos ocuparemos únicamente de la Guía para la clasificación de los datos culturales, editada por George Murdock. George Peter Murdock (1987-1985), ha sido una figura saliente en la antropología norteamericana. Su interés central era la experiencia de investigación empírica, con un gran énfasis en la transculturalidad.

La guía de Murdock fue editada masivamente en 1950 y traducida al español en 1954. En la versión más actual de la misma, cuya introducción redactan Palerm \& Palerm (1989), recuerdan que el primer borrador de dicha guía fue preparado por este mismo autor, que coordinaba un gran grupo de investigadores, a mediados de la década del '30.

El interés de Murdock por la cultura se enfrentaba a uno de los dilemas que expresamos anteriormente referidos a las guías de trabajo de campo, el referido a la posibilidad o imposibilidad de dar cuenta de las transformaciones a partir de estos andamiajes teóricos. Según él mismo sostiene en un trabajo dónde indaga la relación entre sociología y antropología en busca de una ciencia de la cultura.

Es la transmisión de costumbres que asegura la continuidad de la cultura, a pesar de la transitoriedad de la persona. Las costumbres transmitidas de este modo constituyen lo que es llamado de "herencia social" del grupo. Pero la cultura no sólo es continua sino que también es acumulativa. A las nuevas invenciones y aculturaciones desde afuera se añade a la corriente de la cultura en cada generación, y en la mayoría de los casos lo nuevo no desplaza lo viejo (Murdock, 1932, p. 324, traducción propia del inglés).

Esta perspectiva dónde las concepciones inclusivas producen la cultura corre el riesgo de, 
o bien negar la transformación, o bien intentar dar cuenta de lo propio y lo exógeno de los grupos como elementos sin diálogo entre sí. Del mismo modo, sus aportes han sido por momentos de un sofisticado nivel de taxonomización de las pautas culturales (id., 1957; 1937).

Justamente eran sus discípulos quienes se encargaban de emplear la propuesta de la guía en investigaciones concretas y de ese modo perfeccionar los elementos que se incorporaban a través de la misma. Sus propios aportes también constituyeron ejes de transformación de la guía. Los restantes aportes fueron producto, justamente, de la información recopilada por el grupo de investigadores que Murdock guiaba. Esto puede verse, por ejemplo, en los materiales dónde abordó la terminología para la filiación parental de gran diversidad de grupos, intentado dar cuenta de, en cuáles se realizaba diferenciación de género en las categorías de parientes de un mismo grado de distancia biológica (id., 1947). La cantidad de pueblos abordados no permite pensar en la presencia de un investigador en cada campo, sino por el contrario de un enorme equipo, sincronizado y formado para conceptualizar cierto tipo de información.

De este modo la guía fue perfeccionándose y dando lugar al diseño final que se publicara. Sostienen Palerm \& Palerm (ibidem) que las investigaciones que se volcaron en el proceso de producción de la guía incluyeron a ciento cincuenta grupos humanos de diferentes latitudes, documentados en el contexto de un proyecto denominado Cross-Cultural Survey (el propio autor refiere a este proyecto en Murdock, 1940). Estos avances sucedieron durante la década de 1930, pero fue posteriormente, en la siguiente década, cuando el propio gobierno norteamericano solicito la producción de un instrumento de similares características a este grupo de investigadores. Murdock y otros investigadores optaron entonces por enrolarse en el ejército para aportar en la caracterización de poblaciones.

Así fue que algunos de esos materiales se convirtieron en guías de acción para militares norteamericanos que incursionaban en terrenos particulares, por ejemplo aquellos del pacífico que fueran escenario de las guerras con Japón.

La versión de la guía de que disponemos en la actualidad, es producto de un tercer momento de estas investigaciones, cuando el financiamiento del estado norteamericano permitió incrementar la cantidad de miembros incluidos en el proyecto (no solo personas sino universidades). Y cuando las universidades de habla hispana se encargaron de traducir la propia guía para su utilización en estas latitudes y por investigadores locales.

Nuestro interés por estos materiales no solo se inserta en una reflexión metodológica sobre la antropología en términos generales. Además, expresa una necesidad de revisión de los modelos teóricos que se desarrollaron en los contextos en que la antropología como disciplina se consolidó en América Latina. El caso concreto de Argentina expresa en cierta medida esta inserción. Mas allá de su relevancia coyuntural en Estados Unidos, Murdock no es un antropólogo dedicado a la metodología, como aquellos que en cierta medida transformaron la disciplina. Como es obvio, en algunos países de centro América esta guía fue ampliamente utilizada, de hecho fue traducida allí. Por otro lado, su uso en México ha sido notable. En el caso Argentino, muchos de los antropólogos locales que estudiaron y egresaron en los primeros años de esta carrera en universidades nacionales, han realizado sus investigaciones de campo utilizando como parámetro esta guía ${ }^{1}$. Si bien es poco citada en los textos, la guía de George Murdock fue utilizada en las incursiones de 
campo de los antropólogos argentinos de mitad del XX. En conversaciones personales, algunos de los egresados de la primera época de la carrera en Buenos Aires han expresado el valor que la guía Murdock tenía en la formación - dado que era material bibliográfico de las asignaturas cursadas - y en consonancia incidía en las incursiones de campo que ellos mismos desarrollaban en el comienzo de sus trabajos.

\section{Características particulares de la guía Murdock en su tratamiento de la infancia.}

En este texto nos proponemos focalizar especialmente el tratamiento que la guía de George Murdock otorga a los niños y las niñas. La presencia de las niñas y niños en la guía es bastante profusa. Por un lado existe un acápite especial dedicado al tema con la denominación: Infancia y Niñez, el mismo se propone abordar el cuidado, desarrollo físico, tareas y cambios entre el nacimiento y la pubertad. Además de este apartado específico, la niñez aparece también en varios otros, como un eje transversal.

Focalizamos en este aspecto de la guía, como parte de nuestro interés específico en la investigación antropológica con niñas y niños. El interés de la antropología como disciplina científica, por la infancia como grupo de indagación específico transita un período de gran vigor en América Latina en las últimas décadas. Diversos autores se focalizan en indagaciones donde las perspectivas de los niños están en el centro de la escena (Colángelo, 2003; Cohn, 2001; Donoso, 2005; Enriz, 2011; Hecht, 2010; García Palacios, 2005; Larriq, 1993; Leal Ferreira, 2002; Nunes, 2004; Szulc, 2000; Remorini, 2008; Tasinari, 2001; Trpin, 2004). Estas investigaciones recuperan el enfoque etnográfico para acercase a problemáticas muy variadas como los conocimientos religiosos, las diversas apropiaciones lingüísticas, temas de salud, etc.

En consonancia con perspectivas de investigación de otras latitudes, el enfoque etnográfico ha sido la metodología de investigación que mas vigor ha tenido en estas indagaciones. Así mismo, el trabajo de campo etnográfico ha sido la opción más explorada por estas investigaciones, dónde en ocasiones se han incorporado recursos experimentales. El aspecto más fuertemente criticado en estos abordajes es, justamente, la perspectiva adultocéntrica y descalificadora del punto de vista de los niños que parece sostenida en la idea de que los niños no son sujetos validos en la indagación etnográfica (James, 2007).

En tal sentido, el material que abordaremos en esta indagación, la guía de G. P. Murdock, forma parte de aquellos soportes metodológicos dónde la niñez ha sido considerada circunstancialmente, solo para aquellas temáticas dónde su presencia fuera conceptualizada como central y eventualmente interpretada a través de otros actores, los adultos de los propios grupos.

Pero a su vez, por lo minuciosa de su producción la guía de Murdock ofrece el puntapié inicial de un conjunto de producciones que perfectamente podría recuperar el punto de vista de los niños sobre muy diversos fenómenos. Sostenemos que si se parte de concebir a los niños como sujetos activos (Sarmento, 2008) en la producción de conocimiento, se pueden utilizar los parámetros de la guía y desde ellos abordar las perspectivas referidas a temáticas muy variadas. No obstante, vemos claramente que nunca ha sido el objeto de la citada guía ser utilizada para tal fin. Consideramos incluso que la guía no fue concebida para recuperar puntos de vista de los sujetos, sino para aportar a los investigadores en la revisión 
de una enorme cantidad de elementos, desde su perspectiva, sobre la población de que se trate. Empero, las herramientas metodológicas tienen la maleabilidad de permitir a quienes las utilicen una apropiación especial que pueda incluso modificar el curso del soporte y dar lugar a algo nuevo. $\mathrm{Al}$ menos, en eso confiamos.

Comenzaremos ahora por analizar el modo en que son abordados niños y niñas en el apartado especial de la guía, para luego hacerlo desde los otros ejes donde los nińos aparecen. Por último, daremos cuenta de los vacíos explícitos de la propuesta a través de una lectura crítica de la misma.

El apartado no 85 de la Guía para la clasificación de los datos culturales - o Guía Murdock - se denomina, Infancia y Niñez. El mismo se divide a su vez en ocho apartados específicos que focalizan en: disposiciones sociales, ceremonias durante la infancia y la niñez, alimentación infantil, cuidado de los infantes, cuidado de los niños, desarrollo y crecimiento, actividades infantiles, estatus de los niños. Un primer dato relevante es la diferenciación entre infantes y niños. Se considera niños a aquellos que comienzan a "independizarse". En tal sentido, la guía provee, como es de suponer, un concepto de niñez a priori que los investigadores deben rastrear en campo y que supone la posibilidad de cotejar esto en sociedades diversas.

La guía advierte un conjunto de temáticas muy diversas dentro de estas nociones etarias, e intenta dar cuenta tanto de sociedades estatales como de grupos con menor vinculación con las lógicas de los estados. Así, puede pedirse al investigador que dé cuenta tanto de los estatus de cada período y su progresión durante la infancia y la niñez, como de los tribunales de menores. Es decir, la guía intenta dar cuenta de una amplia diversidad de experiencias del ser niño en contextos dónde puede ser la intervención estatal en las familias o bien las ca- tegorías nativas referidas a períodos diversos, las que den cuenta de situaciones particulares de los niños. Lo que no queda suficientemente explicitado es si estos dos escenarios posibles coexisten, o si bien, si puede recuperarse con esta metodología el proceso de transformación de sociedades que, quizá, hayan incorporado recientemente estatutos jurídicos y estén articulando conocimientos muy diversos sobre este caso.

Las disposiciones sociales tienen por objeto central considerar el modo en que los niños y niñas son incluidos en los diferentes grupos, es decir las concepciones sobre parentesco, los rituales de nacimiento o bien de presentación social, etc. En este apartado resalta especialmente que se incida como un elemento saliente la posibilidad de que los niños sean asignados a un pariente masculino (indicado este como sistema poliándrico), pero se da como obvia la posibilidad de que sean las mujeres a quienes se les asigne una filiación de este tipo. En este mismo sentido se indica como relevante la conceptualización de los lazos paternos y se omiten los maternos.

Luego se sistematizan referencias ceremoniales, especialmente aquellas que tienen por objeto simbólico el cuerpo de los niños. No hay aquí menciones a la participación de los niños en ceremonias que no sean focalmente indicadas para ellos, sino en cambio para la población en general.

Respecto de la alimentación en la infancia el eje vertebrador del apartado es el amamantamiento y sus particularidades. Uno de los elementos que considera relevante es la alimentación de las madres durante del período de lactancia. En relación a los cuidados, un aspecto muy relevante en la propuesta de guía es la higiene. $\mathrm{Al}$ respecto se atiende la limpieza y se relaciona ésta con la medicina.

Cuando se aboca a los niños, ya no se atiende a la alimentación. Con relación a los niños 
un aspecto muy relevante es que se inscribe aquí el límite concreto: la pubertad. Respecto de los cuidados, se considera la salud, la vestimenta y los elementos que componen los espacios específicamente dedicados a los niños. Luego el apartado desarrollo y crecimiento, parece tener implícito un modelo de desarrollo, ya que se espera e cumplimiento de acápites, dónde se detalle el retraso en el desarrollo de ciertos aspectos, entre ellos el crecimiento del cabello o la dentición junto con elementos motrices, etc.

El último de los acápites destinados a los niños se dedica justamente al estatus, a la progresión entre distintos momentos dentro del período, así como al modo en que son interpretados dentro de la sociedad de que se trata.

Es paradójico que este apartado, donde puede ponerse en juega la noción particular de niñez se encuentre en el último de los acápites referidos al tema. Del mismo modo, es saliente considerar que no existe mención alguna a las cuestiones de género. Ningún elemento se considera diferenciable, ni tampoco se valora la diferenciación como un elemento socialmente contemplado.

Por otro lado, existen en la guía temáticas muy vinculadas con los niños y niñas, por fuera del acápite específico. Esa es la dificultad central de este tipo de producciones, que en su afán por establecer esquemas, disecciona muy fuertemente áreas del conocimiento que se encuentran muy ligadas.

Tal es el caso del apartado destinado al desarrollo de la personalidad ( $\left.n^{\circ} 155\right)$, que por alguna valoración de los autores supone un apartado especial, y que a su vez incluye muchos elementos referidos a los niños y niñas por un lado y a la adolescencia por otro. Toda vez que logra superar una instancia específica dónde lo psicológico tiene mayor valor, se realizan vinculaciones explicitas a la infancia y niñez (tal como se menciona en la guía) y a la adolescencia como momentos en que el desarrollo de la personalidad atraviesa situaciones particulares.

El apartado que se encarga de la natalidad $\left(n^{\circ} 163\right)$ tiene dos objetivos. Por un lado recuperar lo estadístico. Por otro, tomar elementos del punto del investigador respecto del alumbramiento. Por su parte, el apartado $n^{\circ} 846$, se encarga en particular de los cuidados postnatales. Si bien parte del cuidado referido a las madres, pone cierto énfasis en las acciones destinadas a los niños y el modo en que las mismas se desarrollan.

El referido al juego ( $\left.n^{\circ} 524\right)$ deja implícito que está refiriéndose solo al juego infantil, sino que por el contrario otorga a éste un momento especial dentro de los aspectos que deben registrarse del juego. Por su parte, contempla una taxonomía explicita y se interesa por los objetos de juego.

Por su parte, las nociones de socialización se hacen presentes en el apartado $n^{\circ} 86$. Se encarga aquí el autor de la transmisión de la cultura, y en especial a la socialización de los impulsos y a los procesos educativos menos institucionalizados. Dedica especialmente un acápite a las técnicas de inculcación y disciplinamiento, dónde se propone registrar las acciones adultas que permitan el entrenamiento infantil considerando recompensas, motivaciones, guías, etc.

Dentro del mismo apartado encontramos otro acápite dedicado al destete, y en tal sentido a las normas socialmente establecidas y definidas por los adultos respecto de la alimentación de los pequeños. Luego se encarga de los hábitos de higiene, especialmente los asociados al control de esfínteres. Aquí nuevamente considera las pautas de los adultos respecto de cuándo y cómo dicha tarea debe realizarse. Aquí se agregan además otras actividades de higiene como los baños.

Claro que en virtud de las nuevas perspectivas en antropología de la infancia en el área 
(sobre las que versará la etapa final de este texto y que introdujimos en el inicio de este subtítulo) nos interesa en particular dar cuenta de aquellos acápites donde el punto de vista de los niños podría haber sido recuperado y fue omitido explícitamente.

El primero de ellos es el vinculado con las relaciones familiares $\left(n^{\circ} 593\right)$, es decir con las formas en que los vínculos de parentesco se establecen. En este caso toda la temática está presentada desde el punto de vista de los adultos, el interés del registro parte de las consideraciones y conceptualizaciones que éstos desarrollen respecto de la familia. La perspectiva que pareciera tomarse es estructural. Tampoco hay menciones al punto de vista de los niños respecto de la adopción (apartado $n^{\circ}$ 597). Lo que se propone registrar en este caso son las razones adultas para la citada práctica, el modo en que se desarrolla y sus implicancias en las acciones concretas de la organización familiar toda vez que esta acción se lleve a cabo en cierto grupo.

Este mismo patrón, donde el punto de vista de los adultos es conceptualizado como la perspectiva de la cultura puede aplicarse al apartado destinado a las relaciones ente abuelos y nietos $\left(n^{\circ} 603\right)$ y al destinados a los tíos y sobrinos ( $n^{\circ}$ 604). Al respecto, se enfatiza sobre los poderes de unos y otros en el vínculo, los aspectos formales estructurales de la relación e incluso el vínculo de pares entre primos. En ningún caso se contempla como elemento a considerar las percepciones de los niños al respecto.

\section{Aportes y comentarios a este trata- miento}

La guía de George Murdock ofreció en su época un esquema claro y amplio de las posibilidades de registro temático en las indagaciones de campo. Incluyó una enorme variedad de ejes temáticos y en cada acápite desagrego una variedad detallada.

Pero por otro lado, sus aportes y sistematizaciones se ven enturbiados en cierta medida por elementos de su época y claramente por las lecturas posteriores desde nuevos modelos de abordaje teórico y temático.

Respecto de las dificultades que presentara el uso de la guía en su tiempo las cuestiones referidas a la ética profesional son las que manifiestan mayores obstáculos. En primer término, es claro que el uso de la guía y de los profesionales que dieron lugar a su desarrollo, en el ejercicio y en la prosecución de datos para la colonización militar, política y económica de territorios presenta grandes dilemas éticos. Más aún cuando esta colonización está mediada por guerras y esquemas de exterminio. Obviamente que estos investigadores no serían los únicos científicos que colaborasen con la tarea del ejército norteamericano, sostenemos esto pensado en la enorme cantidad de disciplinas que aportan sus conocimientos al desarrollo de la industria armamentista, especialmente en tiempos de guerra bacteriológica o química. Pero es sabido que para las ciencias sociales la colaboración con estas fuerzas ha presentado dilemas que dieron lugar a virajes completos de sus parámetros de estudio.

Claro ejemplo de esto es la crítica antropológica a aquellos investigadores que aportaran a los ejercicios de dominación colonial por acción u omisión durante los primeros años del siglo XX. Ha sido aquí, la omisión de la noción de poder o la imposibilidad de dar cuenta del propio rol como agente gubernamental, o bien las implicancias de ser quien se es en un contexto de dominación política y económica los focos de mayor interés.

Del mismo modo, además de las tensiones de poder, la guía no permite dar cuenta de las 
tensiones de género en las sociedades abordadas. No da lugar al registro de las particularidades de género y, de un modo clásico, convoca el punto de vista de las mujeres para temas considerados como de mujeres, tal es el caso entre las temáticas analizadas de los temas vinculados con la crianza y socialización.

Pero quizá, el aspecto más saliente de las dificultades que la guía presenta esté asociado a quienes son los sujetos que dan cuenta de las temáticas consignadas, es decir, quienes son las voces convocadas como legítimas en la producción de registros. En este sentido nuestras lectura de la guía nos hace pensar que es la perspectiva del investigador la que es consignada como perspectiva válida respecto de cómo se producen tales o cuales elementos de cierta población. Consideramos que se contempla como cierta la perspectiva del investigador ya que, el registro temático ofrecido no da lugar a contemplar diversas perspectivas sobre un mismo fenómeno.

En el caso particular de la temática en que focalizamos en este trabajo, es decir los abordajes de los niños y niñas en el registro etnográfico producido desde la guía Murdock, las consecuencias pueden tener particularidades. Las perspectivas adultas sobre las tareas, prácticas, experiencias de niños y niñas suelen tener una distancia relevante respecto de las perspectivas que los propios niños tienen sobre esos mismos fenómenos.

Los investigadores del área de la antropología de la niñez, aquellos a los que aludimos en párrafos anteriores, han dado cuenta de las distancias entre percepciones de niños y adultos respecto de distintas acciones. Más aún, si estas reflexiones no solo se contemplan desde perspectivas adultas generales, sino que se consolidan desde perspectivas adultas homogéneas, posiblemente hegemónicas, construidas desde la perspectiva del investigador.
Sería necio pensar que la antropología no ha dedicado su interés a diversas formas de la niñez desde sus orígenes como disciplina. Los niños expresaban una posibilidad a escala de relevar aspectos de la sociedad en general, es decir, hablaban del grupo de que forman parte y reflexionan con cierto extrañamiento sobre muchos preceptos sociales, según los primeros teóricos. Como señala LeVine \& Williams (1974), la etnografía referida a niños en el siglo $\mathrm{XX}$ incluye trabajos en antropología biológica, lingüística y psicológica. En aquellos casos, la niñez solía ser vista como un preludio de lo adulto.

Según destaca Szulc, "La niñez ha sido hasta los 90 un tema marginal en los estudios antropológicos y de las ciencias sociales en general, que no han dirigido su atención a los niños, del mismo modo en que por mucho tiempo excluyeron del análisis a las mujeres" (2006, p.1). Es decir que relevar aspectos de la cotidianeidad de la niñez no necesariamente suponía un abordaje de la niñez, ya que estos abordajes solían depreciar el punto de vista de los niños y niñas.

Algunos de los recorridos de la antropología por las experiencias de los niños y las niñas han estado más atravesados por las perspectivas de la psicología sobre el desarrollo infantil que por abordajes antropológicos, aún cuando los llevaran a cabo antropólogos. El riesgo que han corrido las teorías sobre el desarrollo infantil ha sido el de volverse a-históricas, en su afán por generalizar el desarrollo infantil. Así mismo, las percepciones que pueden extraerse de la guía Murdock, con una mirada tan centrada en la acomodación de distintas culturas a los patrones propuestos, forma parte de esos discursos generales que pierden de vista la transformación y por tanto la perspectiva histórica.

En este sentido, coincidimos con Toren (1993) en que las categorías que los niños y 
niñas utilizan para conocer son tan importantes como las de los adultos y que por tanto, es necesario un registro sistemático de estas cuestiones. Un aspecto de clara vacancia en la propuesta de la guía de campo analizada.

Como bien han puesto de relieve los etnógrafos que la han aplicado, la observación participante con niños tiene la particularidad de que las relaciones de poder sustentadas sobre la diferencia de edad entre el investigador y los "objetos de estudio" constituyen un importante obstáculo para acceder a los mundos infantiles ocultos a los adultos, es decir, a las prácticas sociales, redes de relaciones y sistemas de significados que les son propios y los distinguen como grupo social. La mera decisión de hacer de la población infantil objeto de estudio etnográfico supone una ruptura epistemológica (Bourdieu, 2002) con la perspectiva adultocéntrica, dominante en las ciencias sociales, que considera a los niños y nińas versiones inacabadas, incompletas, proyectadas hacia el futuro, de las personas adultas (adults-in-the-making); efímeros y frágiles apéndices sujetos a un proceso de socialización que camina en un único sentido: los adultos "socializan" y los niños "son socializados" (Ballestín González, 2009).

En el siglo XX, la antropología de la infancia y la niñez creció y se diversificó, con el estudio de campo etnográfico. Esta reseña histórica ha tomado nota de algunas de las principales tendencias y los problemas sin pretender realizar una crítica exhaustiva, analítica, ni una revisión completa de la literatura. Antropólogos pioneros como Malinowski, Mead y Sapir identificaron formas en que la infancia era un sujeto etnográfico digno de atención, y la literatura creció a un ritmo cada vez mayor desde la década de 1920 hasta el presente. Aunque, en un comienzo de la disciplina, una gran cantidad de publicaciones en revistas especializadas emergieron (a los ya citados podríamos agregar
Blodgett, 1893; Boas, 1899; Kroeber, 1916 y 1920), este interés no se mantuvo de forma estable, sino que se desplazó por un tiempo, volviéndose de nuevo relevante para la escuela de cultura y personalidad (Mead, Whiting, Henry, Du Bois). Como vimos, la guía de campo antecede a este interés sistemático.

Ha habido perfiles etnográficos de la niñez en muchos entornos de diferentes sociedades, y los últimos 15 años han visto la publicación de un número sin precedentes de monografías y otros libros. Por otra parte, ha habido estudios especializados sobre el terreno de la niñez, la adopción y las relaciones de los niños, el juego y el idioma, como se mencionó anteriormente.

Desde el principio, los datos etnográficos parecen ser utilizados para observar críticamente algunas formulaciones de la psicología, dando lugar a que la crítica cultural se convierta en un género establecido (Du Bois, 1959a y 1959b). Desde lo metodológico es innegable que la etnografía como metodología central del quehacer antropológico discute la aplicación mecánica - no el uso - de soportes tan rígidos como las guías de campo o los formularios.

Los etnógrafos han documentado la diversidad a través de las poblaciones humanas en la crianza de los hijos, tanto en las normas y prácticas que forman la niñez como en los entornos de referencia, vías de desarrollo de los niños desde el nacimiento hasta la adolescencia. Se han descrito las formas en que los niños aprenden a través de la participación en diferentes entornos sociales y simbólicos, que les permite adquirir significados culturales en los primeros años.

A partir de la década de 1960 la antropología - particularmente la antropología norteamericana - transformó su relación con la niñez y este cambio se plasmó en la etnografía. El interés por la "transmisión" de la cultura (Mead, 
GuÍAS DE CAMPO Y REGISTRO ETNOGRÁFICO | 4I

Bateson, Du Bois, Whiting, Henry) llevó a los antropólogos a establecer nuevos objetivos dentro de la etnografía.

En estos abordajes y reconceptualizaciones, las guías de campo no han tenido ningún lugar, no fueron consideradas, ni tan si quiera fueron citadas para su crítica. Han aportado una perspectiva absolutamente renovadora a las investigaciones. Entre otros elementos, ciertos avances tecnológicos influyeron en esto. La misma Margaret Mead (Bateson \& Mead, 1977) abogó por el uso de registros visuales para profundizar en la comprensión etnográfica de la niñez y, aunque hay disponible una potente tecnología de grabación de video portátil, sólo en raras ocasiones ha sido utilizada fuera de los estudios lingüísticos. Algunos avances en relación al uso de filmaciones para documentar prácticas infantiles destacan que mostrar videos de las prácticas de cuidado de niños y niñas propias de una cultura a los padres y profesores de otra puede provocar no sólo expresiones de conmoción emocional y desaprobación, sino también una explicación espontánea de las hipótesis relativas a los niños y niñas que habían eludido en las entrevistas etnográficas convencionales.

Según destaca la antropóloga brasileña Lopes da Silva (2002), Florestan Fernandes observa, en su abordaje de la niñez, que las sociedades tradicionales privilegian lo que se repite frente a lo que cambia. Fernandes fundamenta esta definición en la participación en las actividades cotidianas y en la asimilación de los valores tradicionales; por eso el énfasis aparece en los ritos de pasaje, entendidos como instancias de cambio controlado por parte de la sociedad. Según los preceptos que Lopes da Silva recupera de Fernandes, en la niñez aparecen manifestadas ideas supremas de personalidad, realidad y una moral menos chocante e impuesta.

\section{Conclusiones}

El aporte de las guías de trabajo de campo ha sido amplio, ya que abordó un gran período de desarrollo de la disciplina, en uno de los contextos más dinámicos de producción de la época de que hablamos, las décadas de 1930, 1940 y 1950. Extenso en un doble sentido ya que los grupos de investigadores que dieron lugar a la constitución de los ejes temáticos y particularidades de las guías, o de la guía Murdock en particular, abordaron al menos ciento cincuenta poblaciones diversas. Además, ha sido extenso su abordaje, ya que, los investigadores que luego se encargaron de las traducciones y revisiones de la misma formaron parte de núcleos de investigación de zonas muy distantes respecto de los lugares dónde la misma fue pensada, consolidada y financiada.

Además, el aporte de las guías de campo ha sido profundo, por las implicancias en la formación de colegas en otras latitudes, contextos y tiempos incluso varias décadas más tarde. Vimos que en el caso argentino y mexicano estas implicancias son claras. Formaron parte de los currículos de formación de las carreras de antropología, en sus etapas de consolidación y constitución.

Estos efectos claros y concretos de las guías no se condicen con la enorme omisión de las mismas en los discursos actuales sobre la disciplina e incluso en las obras dedicada a la historia de la disciplina. En casos que intentamos indagar, las mismas no son siquiera citadas. Quizá, estas afirmaciones no puedan extenderse tan gratuitamente a toda la región, por tanto valdría la pena intentar reflexiones desde academias locales, a fin de conocer con más profundidad y fundamento en qué medida propuestas que han sido desarrolladas para la dominación fueron utilizadas con otros objetivos en nuestra 
región, dónde el uso fue expresamente de indagación teórica. Por último, la homogeneidad como resultado de las investigaciones ha sido una marca de estas propuestas y de ese impacto en las investigaciones locales es importante conocer aún más.

Este trabajo ha perseguido un doble objetivo, por un lado poder mostrar los alcances y aportes que las guías pueden ofrecer al trabajo de campo. Pero, por otro lado, las limitaciones que las mismas han tenido como propuesta y como implementación concreta.

En este sentido, reafirmamos que los recorridos recientes de la antropología por las experiencias de los niños y las niñas, especialmente en América Latina, presentan un auge como temática de investigación en las últimas décadas. Estos aportes brindan a los estudios referidos a la infancia una perspectiva diacrónica y plural, que permite dejar a un lado las miradas monolíticas. En este sentido consideramos que deben acomodarse las propuestas de las guías de campo a un registro que permita dar cuenta de modelos interculturales. Así también queremos reafirmar la relevancia de incorporar las categorías que los niños y niñas utilizan para entender el mundo como elementos centrales del análisis. Las nociones con que los sujetos de una investigación entienden el mundo no pueden sino brindarnos el punto de partida de las preguntas significativas para éstos.

Guias de campo e registro etnográfico. Uma revisão da abordagem das crianças a partir do Guia para a classificação dos dados culturais

resumo Estudos que tiveram por epicentro a comparação dos grupos populacionais formaram parte da espinha dorsal da antropologia como dis- ciplina. No contexto de estudos comparativos, em meados do século XX, o uso de guias de campo nos estudos etnográficos locais foi regular. Neste trabalho, propomos abordar o contexto e a forma de sua produção, tendo como foco de análise o guia de George Murdock, que foi uma ferramenta de formação de antropólogos nos primórdios da antropologia como uma carreira de estudos sistemáticos. A abordagem considerará, especialmente, o lugar atribuído às crianças no guia de Murdock. Consideramos em contraste essa abordagem e a perspectiva atual para o estudo desses grupos.

palavras-chave Etnografia. História da teoria. Guias de campo. Antropologia local. Antropologia da Infância.

Fieldwork guides and ethnographic register. A revision on the approach to children in the Guide for the classification of cultural data

abstract Comparative studies have been the backbone of the formation of anthropology as a discipline. Within the comparative studies of the mid-twentieth century, the use of fieldwork guides in local ethnographic is common. The aim of this paper is to address the context and the production of the guides, considering as a central point of analysis George Murdock's guide. This guide has been a relevant tool in the local training of anthropologists, in the beginnings of anthropology as a career of systematic studies at the university. The approach to the guide is going to be focused the particular way that children are considered in this guide. In this paper we are going to consider the contrast between this kind of approach and the current outlook for the study of these groups of populations.

keywords Ethnography. History of theory. Field guides. Local anthropology. Anthropology of Childhood. 


\section{Notas}

1. No solo ello, sino que atentos a los tiempos que corrían en Tucumán se desarrollo una guía propia. Se encargó de ella el entonces director del Instituto de Antropología de la Universidad Nacional de Tucumán, Radamés Altieri (para ampliar, ver Perazzi, 2003; Carrizo, 2010).

\section{Referências bibliográficas}

ALVARGONZÁLEZ, David. Del relativismo cultural y otros relativismos. El escéptico. La revista para el fomento de la razón y la ciencia. Espanha, n.3, 0. 8-13, 1999.

BALANDIER, Georg. Antropología Politica. Buenos Aires: Ediciones del Sol, 2004.

BALLESTÍN GONZÁLEZ, Beatrice. La observación participante en primaria: ¿̨un juego de niños? Dificultades y oportunidades de acceso a los mundos infantiles. Revista de antropología iberoamericana. Madrid, v. 4, n. 2., p. 229-244, 2009.

BATESON, George \& MEAD, Margaret. Margaret Mead and Gregory Bateson on the Use of the Camera in Anthropology. Studies in the Anthropology of Visual Communication, v. 4, n. 2, 1977.

BLODGETT, James H. The Rural School Problem. American Anthropologist, v. 6, n. 1, p. 71-78. 1893.

BOAS, Franz. Review of Mac Donald, Arthur: Experimental Study of Children. American Anthropologist, New Series, v. 1, n. 4, p. 773-775, 1899.

BOURDIEU, Pierre. El oficio del sociólogo. Buenos Aires: Siglo Veintiuno, 2002.

CARRIZO, Sergio. Documentos, Quipus, clases e indios. Andrés Radamés Altieri en el Instituto de Antropología de la Universidad Nacional de Tucumán. Revista del Museo de Antropología, Córdoba, Argentina, n. 3, p. 239-250, 2010.

COHN, Clarice. Crescendo como um Xikrin: uma análise da infância e do desenvolvimento infantil entre os Kayapó-Xikrin do Bacajá. Revista de Antropologia, 43(2), 2000.

COLÁNGELO, María Adelaida. La mirada antropológica sobre la infancia. Reflexiones y perspectivas de abordaje: Mesa: Infancias y juventudes. Pedagogía y formación. SEMINARIO INTERNACIONAL LA FORMACIÓN DOCENTE ENTRE EL SIGLO XIX. Buenos Aires. (Mimeo). 2003.
DaMATTA, Roberto. El oficio del Etnólogo o cómo tener "Anthropological Blues". In: BOIVIN, M.; ROSATO, A. \& ARRIBAS, V. (comp.). Constructores de otredad. Una introducción a la Antropología Social y Cultural. Buenos Aires: Editorial Antropofagia, 2004.

DONOSO, Carla. Buscando Las Voces De Los Niños/As Viviendo Con Vih: Aportes Para Una Antropologia De La Infancia. I CONGRESO LATINOAMERICANO DE ANTROPOLOGÍA. Rosario, Argentina. 11 al 15 de Julio de 2005.

DU BOIS, Cora. The cultural interplay between East and West. EAST AND WEST MUST MEET. Symposium. The Michigan State University Press, 1959a.

DU BOIS, Cora. Social Forces in southeast Asia. Cambridge: Harvard University Press, 1959 b.

ENRIZ, Noelia. Jeroky Porä, Juegos Saberes y Experiencias infantiles Mbyá guarani en Misiones. Muenchen: Lincom Europa, 2011.

FROW, John. Cultural Studies \& Cultural Value. Oxford: Oxford University Press, 1992.

GARCÍA PALACIOS, Mariana. ¿Qué puede decir la antropología acerca del punto de vista de los niños en un estudio sobre religión?. $1^{\circ}$ CONGRESO DE LA ASOCIACIÓN LATINOAMERICANA DE ANTROPOLOGÍA. Rosario, 2005.

GEERTZ, Cliford. La Interpretación de las culturas. Barcelona: Gedisa, 2001.

GLEDHILL, John. El poder y sus disfraces. Barcelona: Ediciones Bellaterra, 2000.

HECHT, Ana Carolina. "Todavia no se hallaron hablar en idioma" - Procesos de socialización lingüística de los niños en el barrio toba de Derqui (Argentina). Muenchen: Lincom Europa, 2010.

HENRY, Jules y Zunia. Doll Play Of Pilagá Indian Children. New York: Vintage Books, 1974.

JAMES, A. Giving voice to children's voices: Practices and problems, pitfalls and potentials. American Anthropologist, v. 109, n 2, p. 261-272, 2007.

KROEBER, Alfred L. Games of the California Indians. American Anthropologist, New Series, v. 22, n. 3. p. 272-277, 1920.

. The Speech of a Zuñi Child. American Anthropologist, New Series, v. 18, n. 4, p. 529-534, 1916.

LAMAS, Marta. La categoría feminista y la categoría "genero". Nueva Antropología, México, v.8, n.30, p.173198, 1986.

LARRIQ, Marcelo. Ipytüma construcción de la persona entre los Mbya-guarani. Misiones: Editorial Universitaria / UNaM, 1993. 
LeVINE Robert A. \& WILLIAMS, Price. Children's Kinship Concepts: Cognitive Development and Experience Among the Hausa. Ethnology, v. 13, n. 1, p. 25-44, 1974.

LOPES DA SILVA, Aracy. 2002. Pequenos "xamās": crianças indígenas, corporalidade e escolarização. In: LOPES DA SILVA, Aracy; MACEDO, Ana Vera Lopes da Silva \& NUNES, Ângela (Orgs.). Crianças indigenas: ensaios antropológicos. São Paulo: Global, 2002. p. 37-63.

MEAD, Margaret. Sexo y temperamento. Barcelona: Editorial Paidós, 1985.

MOORE, Henrietta. Antropologia y Feminismo. Madrid: Ediciones Cátedra, 1999.

MURDOCK, George Peter. The Science of Culture. American Anthropologist, New Series, v. 34, n. 2, p. 200-215, 1932.

Comparative Data on the Division of Labor by Sex. Social Forces, v. 15, n. 4, p. 551-553, 1937.

The Cross-Cultural Survey. American Sociological Review, v. 5, n. 3 p. 361-370, 1940.

Bifurcate Merging, a Test of Five Theories. American Anthropologist, New Series, v. 49, n. 1, p. 56-68, 1947.

World Ethnographic Sample. American Anthropologist, New Series, v. 59, n. 4, p. 664-687, 1957.

NUNES, Angela. Brincando de ser criança, contribuçôes da etnologia brasileira à antropologia da infancia. Tese de doutorado - Faculdade de Filosofia, Letras e Ciências Humanas, Universidade de São Paulo, 2003.

PALERM, Angel \& PALERM, JuanVicente. Guía para la clasificación de los datos culturales. Colección de Antropología Social, Serie Manuales n. 1. Universidad Autónoma Metropolitana - Iztapalapa / Departamento de Antropología, 1989.

PIRES, Flavia. Ser adulta e pesquisar crianças: explorando possibilidades metodológicas na pesquisa antro- pológica. Revista de Antropologia, São Paulo, v. 50, n. 1, p. 225-270, 2007.

REMORINI, Carolina. Aporte a la Caracterización Etnográfica de los Procesos de Salud-Enfermedad en las Primeras Etapas del Ciclo Vital, en Comunidades Mbya-Guarani de Misiones. Tese (Doutorado) - Argentina, Facultad de Ciencias Naturales y Museo, Universidad Nacional de La Plata, 2008.

SARMENTO, Manuel. "Estudos da criança" como campo interdisciplinar de investigação e conhecimento. Revista INTERACÇÕES, n. 10, p. 1-5, 2008.

SZULC, Andrea. La construcción social de la nińez en Chacabuco (Provincia de Buenos Aires). VI CONGRESO ARGENTINO DE ANTROPOLOGÍA SOCIAL. Mar del Plata, Argentina, 2000.

Antropología y Niñez, la omisión de las culturas infantiles. In: WILDE, G. \& SCHAMBERT, P (Eds.). Cultura, comunidades y procesos contemporáneos. Buenos Aires: Editorial SB, 2006.

TASSINARI, Antonella. Escola indígena: novos horizontes teóricos, novas fronteiras de educação. In: LOPES DA SILVA, Aracy \& LEAL, Mariana Kawall Ferreira (Orgs.). Antropologia, História e Educação - A questão indígena e a escola. Sáo Paulo: Global, 2001. p. 44-70.

TOREN, Christina. Making History: the significance of childhood cognition for a comparative anthropology of mind. Man, New Series, v. 28, n. 3, p. 461-478, 1993.

TRPIN, Verónica. Aprender a ser chilenos. Identidad, trabajo y resistencia de migrantes en el Alto Valle de Río Negro. Buenos Aires: Editorial Antropofagia, 2004.

WHITING, Beatrice B. \& WHITING, John W. Children of six cultures: A psycho-cultural analysis. Cambridge, MA: Harvard University Press, 1975.

\section{autora Noelia Enriz}

Professora da Universidade Nacional de Lomas de Zamora

Doutora em Antropologia Social / UBA

Recebido em 25/02/2012

Aprovado para publicação em 01/10/2012 